\title{
Shear-wave Velocity Model from Rayleigh Wave Group Velocities Centered on the Sacramento/San Joaquin Delta
}

\author{
Jon B. Fletcher ${ }^{1}$ (D) and Jemile Erdem ${ }^{1}$
}

\begin{abstract}
Rayleigh wave group velocities obtained from ambient noise tomography are inverted for an upper crustal model of the Central Valley, California, centered on the Sacramento/San Joaquin Delta. Two methods were tried; the first uses SURF96, a least squares routine. It provides a good fit to the data, but convergence is dependent on the starting model. The second uses a genetic algorithm, whose starting model is random. This method was tried at several nodes in the model and compared to the output from SURF96. The genetic code is run five times and the variance of the output of all five models can be used to obtain an estimate of error. SURF96 produces a more regular solution mostly because it is typically run with a smoothing constraint. Models from the genetic code are generally consistent with the SURF96 code sometimes producing lower velocities at depth. The full model, calculated using SURF96, employed a 2-pass strategy, which used a variable damping scheme in the first pass. The resulting model shows low velocities near the surface in the Central Valley with a broad asymmetrical sedimentary basin located close to the western edge of the Central Valley near $122^{\circ} \mathrm{W}$ longitude. At shallow depths, the Rio Vista Basin is found nestled between the Pittsburgh/ Kirby Hills and Midland faults, but a significant basin also seems to exist to the west of the Kirby Hills fault. There are other possible correlations between fast and slow velocities in the Central Valley and geologic features such as the Stockton Arch, oil or gas producing regions and the fault-controlled western boundary of the Central Valley.
\end{abstract}

Key words: Crustal structure, ambient noise tomography, seismic hazard.

\section{Introduction}

The Sacramento/San Joaquin Delta (henceforth referred to as the Delta), located just east of San Francisco, is the confluence of the Sacramento and

Electronic supplementary material The online version of this article (doi:10.1007/s00024-017-1587-x) contains supplementary material, which is available to authorized users.

1 US Geological Survey, 345 Middlefield Rd., Menlo Park, CA 94025, USA. E-mail: jfletcher@usgs.gov
San Joaquin rivers near the western edge of the Central Valley and east of the Coast Ranges. It provides half of California's fresh water supply. About $1600 \mathrm{~km}$ of levees surrounding low-lying islands now protect agriculture and population in the Delta. If these levees were to fail, brackish water from the San Francisco Bay would inundate the islands and contaminate the fresh water supply. Shaking from local earthquakes may pose a significant threat to the failure of the levees. To develop a more comprehensive seismic risk assessment, we have constructed a shear-wave velocity model of the region around the Delta to permit the computer simulation of shaking in the Delta from nearby earthquakes. We have included the region around the Delta to allow some comparison between structures in the Delta to that just outside and to provide model space that includes local faults that may be locations for potential sources. The goal is to have a model that incorporates basins and basement features that can be correlated with geology and geophysics and that will likely affect the character of shaking in the Delta.

To this end, Fletcher et al. (2016) used ambient noise tomography to determine the spatial distribution of Rayleigh wave group velocities (Campillo and Paul 2003; Shapiro et al. 2005; Fletcher et al. 2016) in the Central Valley, CA centered near the Delta. In this paper, we invert the Rayleigh group velocities to build a 3-D shear-wave velocity model. This paper explores the use of two algorithms; one that employs a linear least squares approach and one that is a global optimization algorithm. Other methods include Barmin et al. (2001) and Shapiro and Ritzwoller (2002) who more generally focus on global datasets (see Romanowicz 2002, for a review). The dispersion data range from about 4 to $18.5 \mathrm{~s}$ with depth 
sensitivity from 1 to $2 \mathrm{~km}$ to about $20 \mathrm{~km}$. For this model, the dispersion data did not meet signal to noise criteria below about $4 \mathrm{~s}$, and consequently higher mode data and shallow profiles will be needed to develop a better model for the upper $1 \mathrm{~km}$ or so.

\section{Regional Geologic Structure}

The geologic structure of the Great Valley and the Coast Ranges to the west reflects its history as a subducting margin (Atwater 1970; Constenius et al. 2000; Godfrey and Klemperer 1998) during the Mesozoic and early Tertiary. The various formations exposed in the Coast Ranges, such as the Franciscan, Coast Range ophiolite and Great Valley sequence make up a subduction assemblage from that tectonic environment (Constenius et al. 2000) of Mesozoic age. Starting about $30 \mathrm{My}$ ago subduction of the Farallon Plate ceased (Atwater 1970) and movement on the San Andreas commenced. The Central Valley is mostly made up of the Great Valley sequence, which is marine clastic rocks of late Mesozoic and early Tertiary age (Bartow and Nilsen 1990). The Great Valley sequence was deposited in a forearc basin situated between the eastern Sierran magmatic rocks and the western Franciscan rocks. Now the Great Valley is an oil and gas producing synclinal basin with the deepest point near the western edge. The Great Valley can be split into northern and southern segments that are separated by the Stockton arch, a basement high that crosses the valley just south of the Sacramento/San Joaquin Delta (Bartow and Nilsen 1990). The western margin of the Great Valley appears controlled by active local faults including the Pittsburgh and Kirby Hills faults just east of the Montezuma Slough, the Greenville fault just east of the Calaveras and the Midland and west Tracy faults which are located in the Delta.

\section{Rayleigh Wave Group Velocity Model}

Fletcher et al. (2016) processed ground motion recordings for ambient noise tomography using an array of 14 broadband seismometers in or near the Delta together with broadband stations from the
Berkeley Digital Seismic Network and the Transportable Array of Earthscope; a total of 31 stations (see Fig. 1). The time period covered is between 2006 and 2013 with various configurations to the number of stations and arrays being used (Fletcher et al. 2016). Ambient ground motion data spanning from 8 months to over a year were processed to create dispersion curves between all pairs of stations and then inverted for a 3-D grid of Rayleigh wave velocities as shown in Fig. 2. In general, slower velocities are found in the Central Valley compared to either the Coast Ranges to the west or Sierra Nevada Mountains to the east. The correlation to geologic features, particularly faults at the western boundary of the Central Valley is strong. The array is designed to be centered on the Delta, but also to extend well beyond the Delta so that its structure fits within a geologic context. The model space is $101 \times 101$ cells that cover a total of $5.0^{\circ}$ in each dimension centered on the Delta. Each cell is about $5 \mathrm{~km}$ in width $\left(0.05^{\circ}\right.$ ). Figure 3 (from Fletcher et al. 2016) shows the weights used in the inversion for Rayleigh wave velocities. The weights are determined from the time spent in each cell and reflect the uneven array geometry. In this paper, we invert the dispersed Rayleigh group velocities using two algorithms that complement each other, as one is linear and sensitive to the starting model, whereas the other uses a starting model that is randomly generated and is based on an optimization algorithm.

\section{Linearized, Least Squares Approach}

We used an inversion code called SURF96 to invert Rayleigh wave dispersion curves for a model that consists of horizontal homogeneous isotropic layers (Herrmann 2013). The inversion program is an iterative, linearized, least squares approach based on Russell (1987) and has been used by others to invert for structure (Warren et al. 2008). The inversion gives explicit control on whether the depth of the horizontal interfaces are solved for or kept at the starting model. It also allows control over whether a differential smoothing constraint is used. At each node, a dispersion curve is formed using the Rayleigh wave group velocities at the resolved periods. Figure 4 


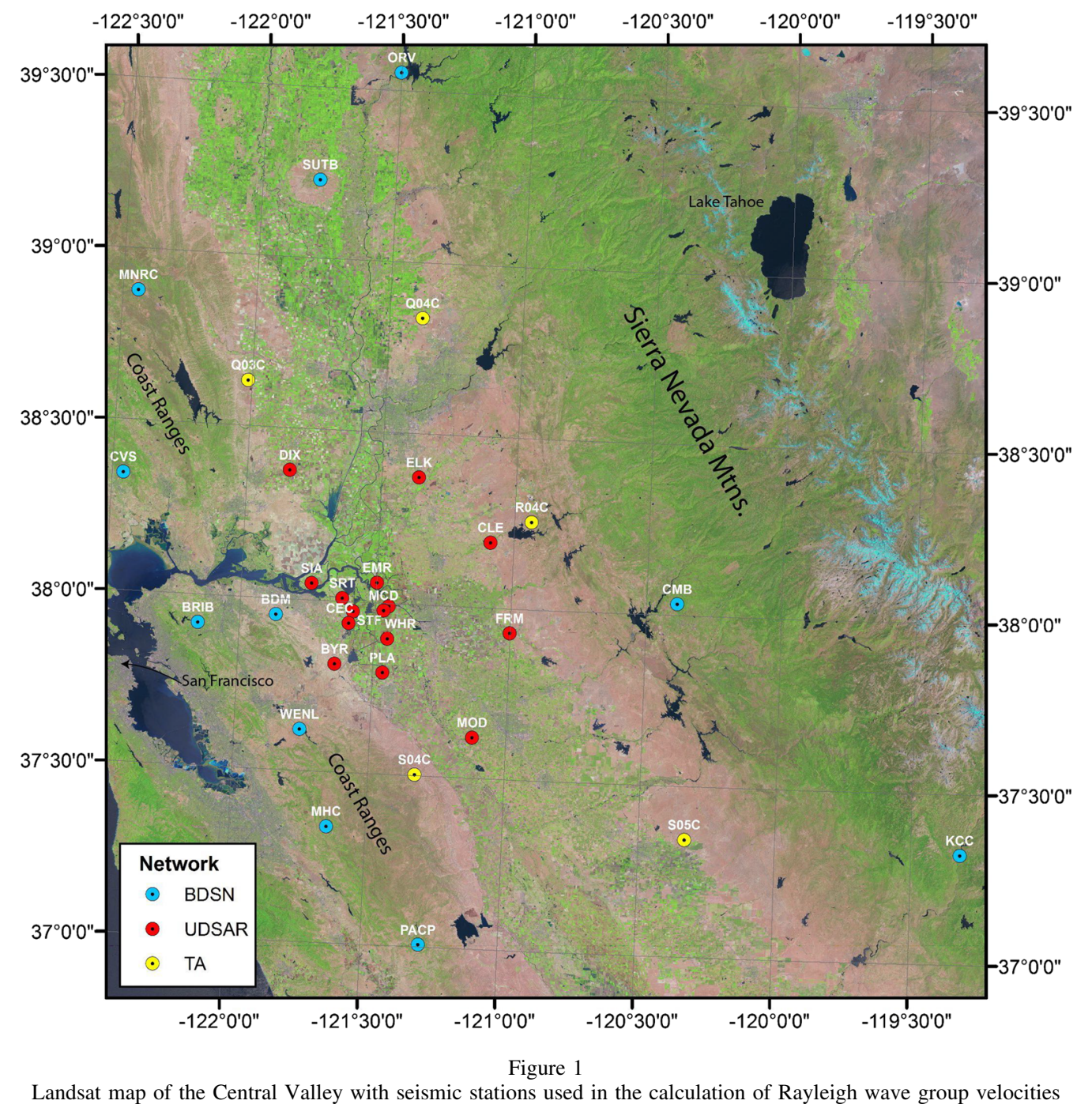

shows a fairly typical dispersion curve for a region (Coast Ranges) with a smooth increase in velocity from a low of $1.6 \mathrm{~km} / \mathrm{s}$ at $3 \mathrm{~s}$ to more than $2.6 \mathrm{~km} / \mathrm{s}$ at $17 \mathrm{~s}$. This original data (at $1 \mathrm{~s}$ spacing) has been interpolated by a factor of four (spacing at $0.25 \mathrm{~s}$ ) before entering the inversion. The starting model uses a 1-D (vertically variable) velocity structure with 13 homogeneous layers extending to $24.5 \mathrm{~km}$ depth and a 14th layer as the half space (see Table 1). The starting model includes some low shear-wave velocities near the surface based on Gibbs et al. (2001) as well as curves from Nafe and Drake (1957). Included in the starting model are values for P-wave velocity, S-wave velocity, density, and $Q$. The algorithm maintains the $V \mathrm{p} / V \mathrm{~s}$ values of the starting model for each layer and inverts for density. $Q$ was set to a high value (500) and not inverted for. The starting model was constructed to provide a modest gradient in properties approximated by the generally increasing values of velocity for each layer. The layers near the surface, in particular, are thinner because of the higher gradient expected near the surface (Gibbs et al. 2001).

The program was run twice to accommodate certain profiles that did not invert easily (high final error). The first time the inversion ran in four steps (a step is one command line that instructs the program to invert for velocity or several other possibilities 

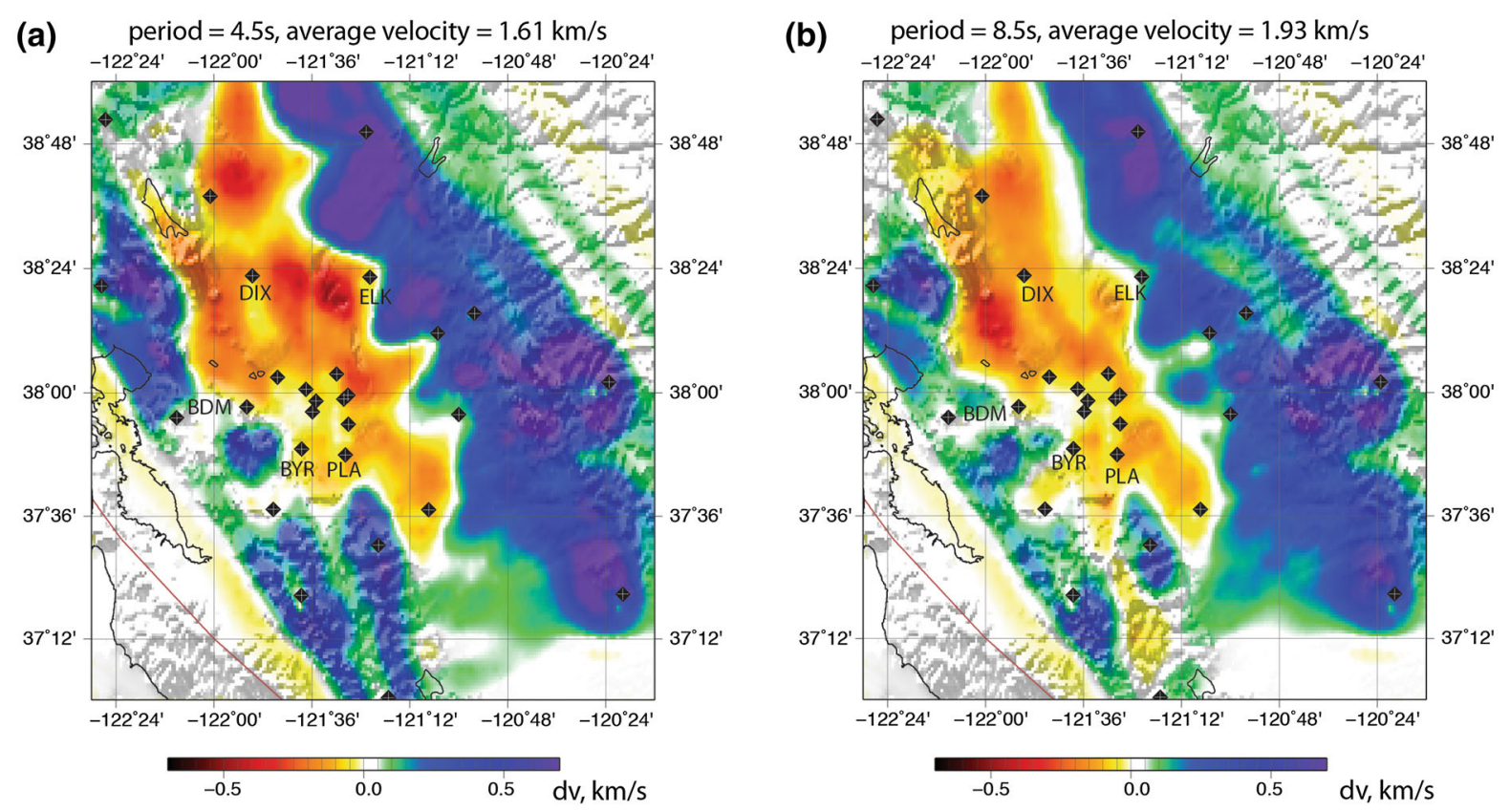

(c) period $=12.5 \mathrm{~s}$, average velocity $=2.28 \mathrm{~km} / \mathrm{s}$
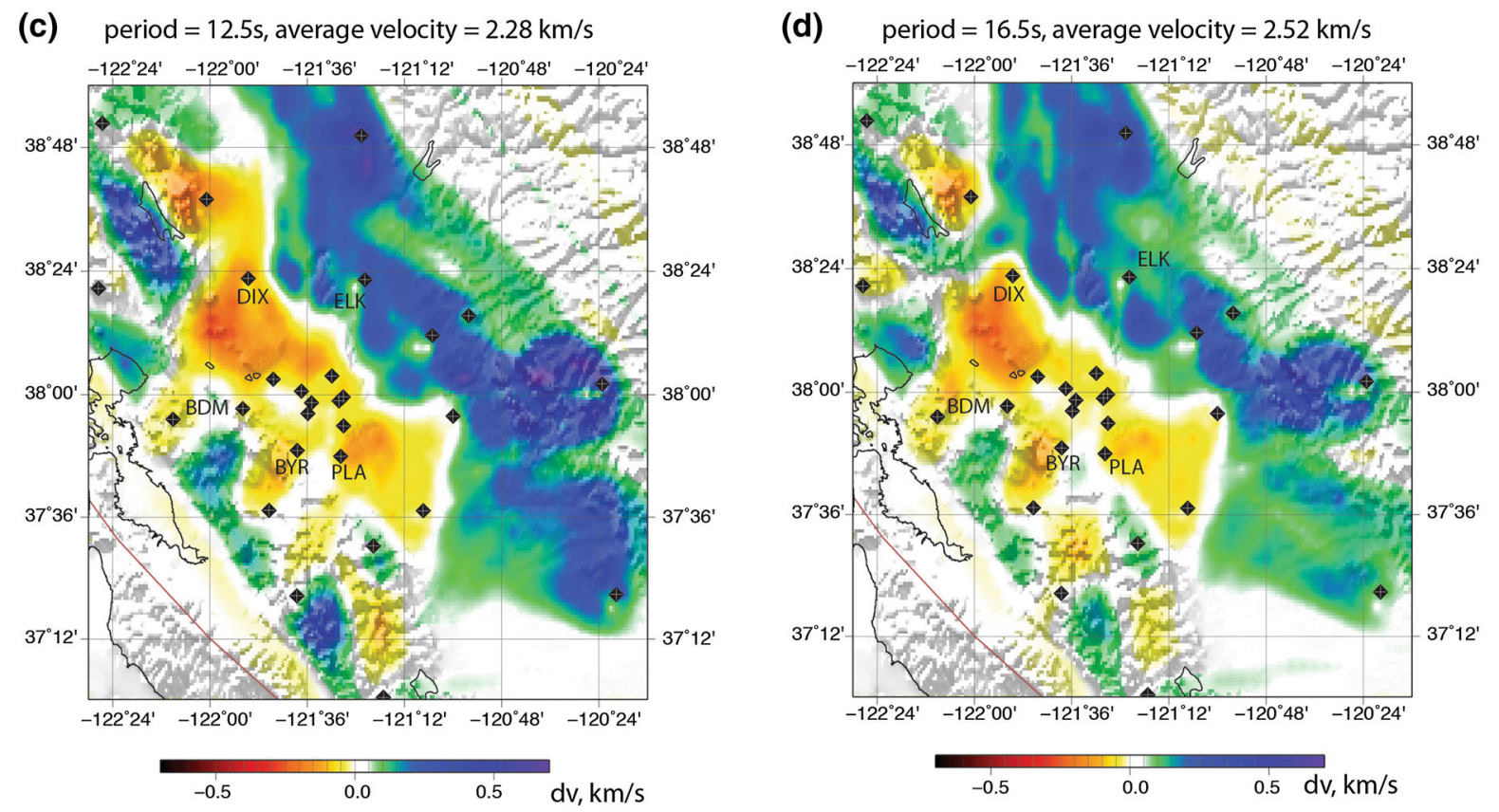

Figure 2

Examples of Rayleigh wave velocities that were inverted for shear-wave velocity. These data are from Fletcher et al. (2016) and are the result of an inversion of all dispersion data between all pairs of stations. See Fletcher et al. (2016) for correlation of changes in Rayleigh wave velocity and geologic features in the Central Valley, CA

such as layer thickness) and at each step we increased the damping from 0.3 to 1.0 (each time by 0.2 except the last at 0.3 ) with the goal of achieving a stable final model. In the first step, we use eight groups of commands to alternately solve for velocity and layer thickness or just velocity. At each successive step, we 


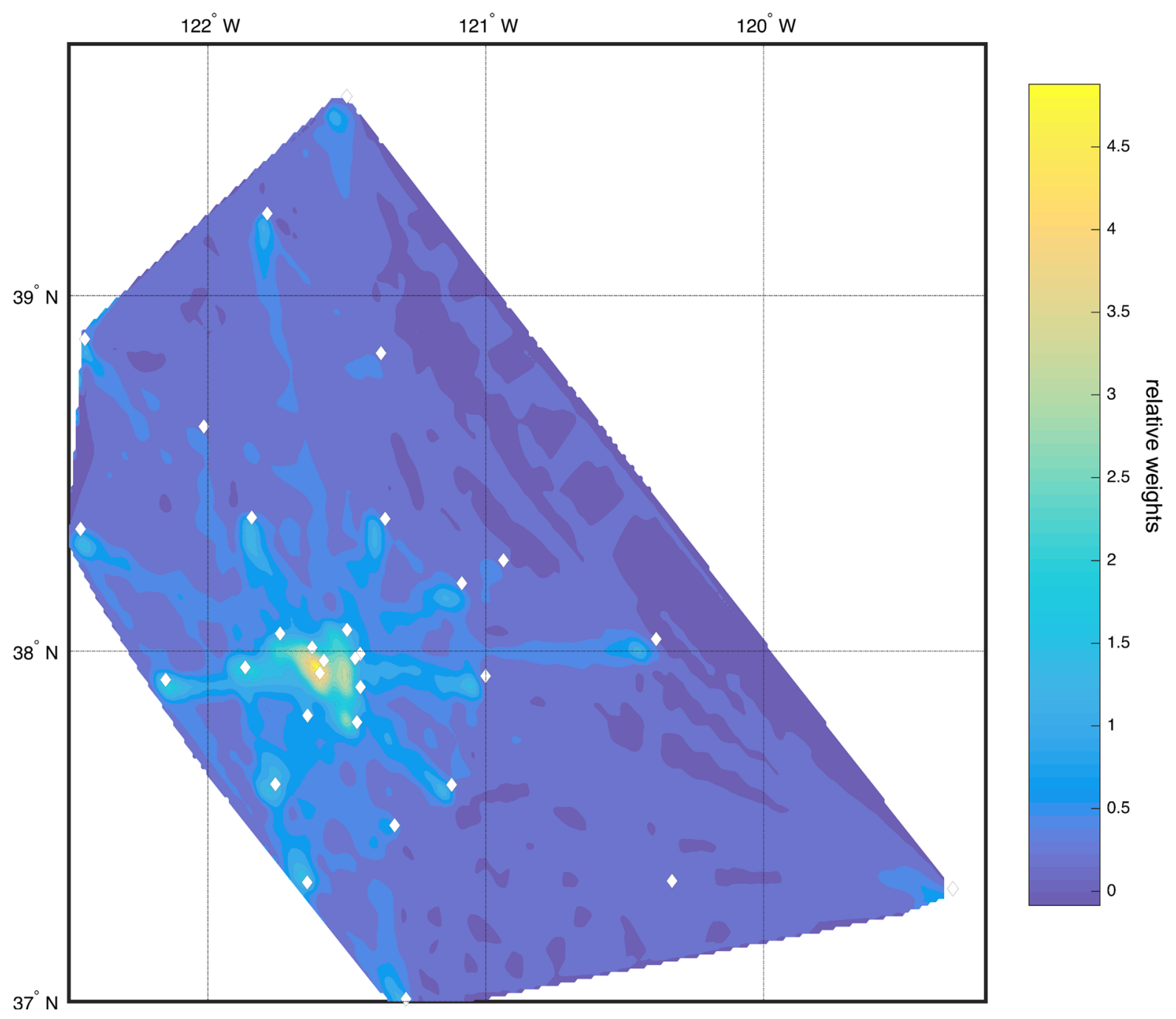

Figure 3

Weights used in the inversion for Rayleigh wave velocity. The weights are the cumulative time spent in each cell

reduce the number of commands, reduce how often it solves for thickness, and increase the damping. This was done to avoid converging too fast on a less than best model. After this attempt we check all nodes for goodness-of-fit. For all nodes where the fit was worse than $98 \%$ (in fitting the dispersion curve), the code is rerun with a simpler scheme. In the second run, we used just five groups of commands that solve for velocity or layer thickness and a damping of 0.3 . At the end, all nodes $(101 \times 101)$ were fit to better than $98 \%$.

Figure 4 also shows the fit to the dispersion data. The fit is remarkably good, though visually the shortest periods are not quite fit as well. The left side of the figure shows the starting model and ending model. For this data, the ending model moved to higher velocities compared to the starting model, and has a sharp gradient near the surface $(0.7 \mathrm{~km} / \mathrm{s})$. The final model, discussed later, was constructed using the above procedure.

However, this method does not provide a straightforward estimate of uncertainty. Different starting models could be tried, but only some starting models would produce a stable result. Consequently, the models would need to be selected carefully, biasing the result. One tactic would be to use fewer 


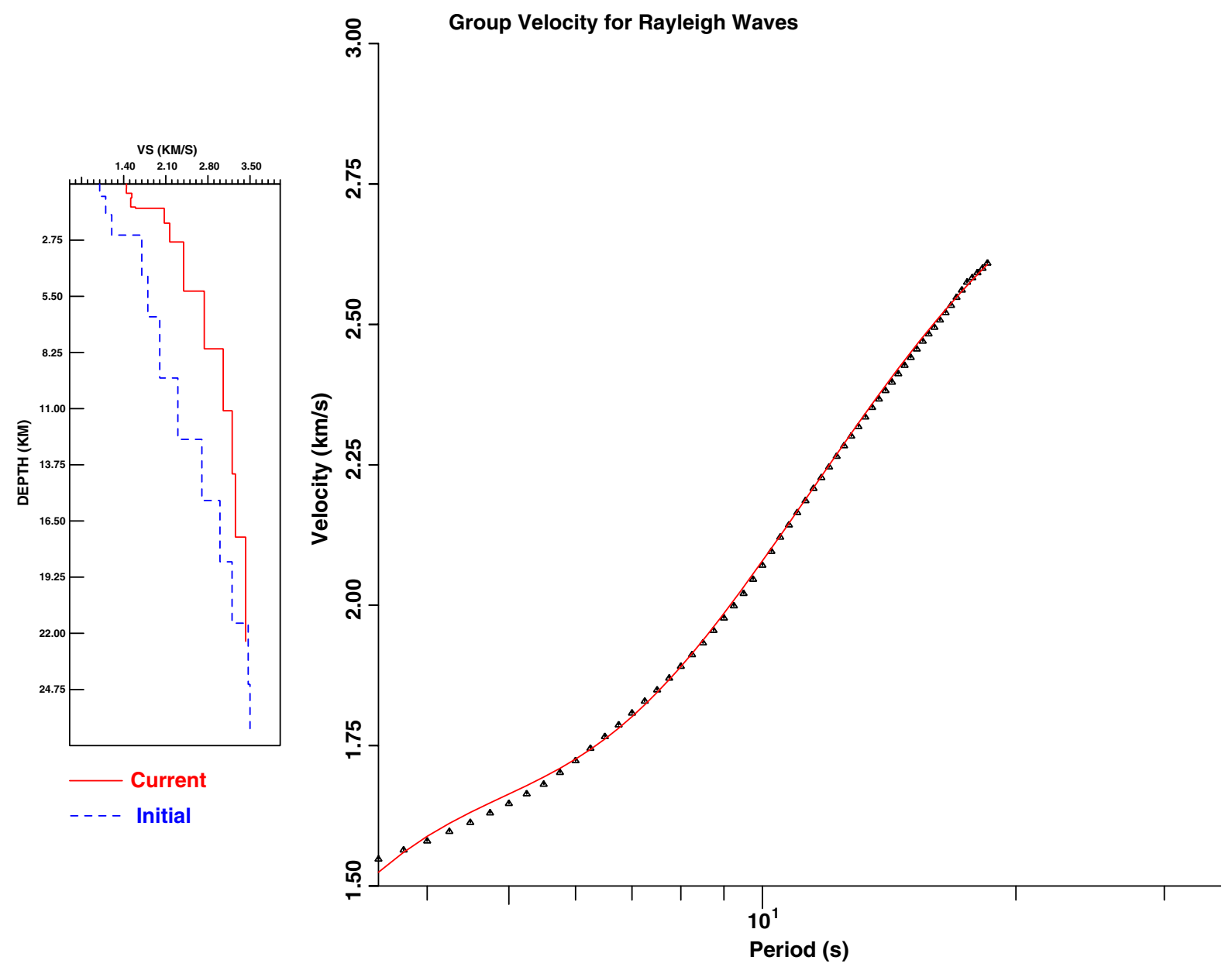

Figure 4

Observed dispersion curve, fit to the data using the best-fit model and the corresponding shear-wave velocity model. Both the starting model and ending model are shown

layers, but the number chosen is necessary to produce the expected gradients near the surface. In light of these concerns, we also tested an optimization algorithm that tries many models during a run and selects the best-fitting models to project to the end. These optimization schemes are better at estimating errors because many models that fit a certain criteria (such as goodness-of-fit) can be grouped and for which a variance can then be calculated.

\section{Genetic Inversions}

To this end, we used the genetic code documented in Yamanaka and Ishida (1996) to invert three nodes for 1-D shear-wave velocity models (Goldberg 1989, Sen and Stoffa 1992) to compare to the previous output. This algorithm is a global optimization system in comparison to a linear, least squares inversion. Genetic algorithms as well as simulated-annealing algorithms have the primary benefit that they are able to find a range of unbiased models that fit to some criteria. In both methods, the starting model is a random model and not sensitive to the user biases. In both methods, a set of parameters have to be set that describe the number of layers and the range of velocities for each layer that the algorithm will search. The genetic code uses an L2 norm for a fit function (the dispersion curve). Yamanaka and Ishida (1996) invert synthetic and actual Love wave data for 
Table 1

Starting Model, SURF96

\begin{tabular}{llllll}
\hline $\begin{array}{l}\text { Layer thickness } \\
(\mathrm{km})\end{array}$ & $\begin{array}{l}V \mathrm{p}(\mathrm{km} / \\
\mathrm{s})\end{array}$ & $\begin{array}{l}V \mathrm{~s}(\mathrm{~km} / \\
\mathrm{s})\end{array}$ & $\begin{array}{l}\text { Density }(\mathrm{g} / \\
\mathrm{cc})\end{array}$ & $Q \mathrm{p}$ & $Q \mathrm{~s}$ \\
\hline 0.3 & 1.9 & 1.0 & 1.6 & 500 & 500 \\
0.3 & 2.0 & 1.0 & 1.8 & 500 & 500 \\
0.3 & 2.2 & 1.1 & 1.8 & 500 & 500 \\
0.6 & 2.2 & 1.1 & 2.0 & 500 & 500 \\
1.0 & 2.3 & 1.2 & 2.1 & 500 & 500 \\
2.0 & 2.8 & 1.7 & 2.2 & 500 & 500 \\
2.0 & 3.2 & 1.8 & 2.3 & 500 & 500 \\
3.0 & 3.7 & 2.0 & 2.4 & 500 & 500 \\
3.0 & 4.2 & 2.3 & 2.5 & 500 & 500 \\
3.0 & 4.5 & 2.7 & 2.6 & 500 & 500 \\
3.0 & 5.2 & 3.0 & 2.6 & 500 & 500 \\
3.0 & 5.5 & 3.2 & 2.6 & 500 & 500 \\
3.0 & 6.0 & 3.47 & 2.7 & 500 & 500 \\
0.0 (half space) & 6.0 & 3.5 & 2.7 & 500 & 500 \\
\hline
\end{tabular}

a 1-D model. This program has been modified to invert Rayleigh wave group velocities. The genetic algorithm starts with a given set of possible values (e.g., a set of values for velocity). In the genetic method, possible choices are coded in binary (for example, the second possible velocity in a range that has three choices would be coded 10). All the binarycoded parameters are then put end-to-end to develop a chromosome (each model). In each generation, the code keeps track of the best-fitting model and mutates the present set of chromosomes (changes a 0 to a 1 and vice versa). The best model which fits the dispersion data with an L2 norm from early generations then proceeds to the next generation. The chromosomes are mutated in two different ways (see Yamanaka and Ishida 1996) to also develop new individuals in each generation while retaining the best model from the previous generation. The program assumes a $V \mathrm{p} / V \mathrm{~s}$ ratio that decreases with depth. We changed the original algorithm to $V \mathrm{p}=400+1.6 V \mathrm{~s}$. This relationship seemed to match the assumed decrease of $V \mathrm{p} / V \mathrm{~s}$ with depth that was input to SURF96. We provide estimates of density in the input files. We tried changing the fitness function to include a penalty for non-smooth models by squaring the difference between velocities of adjacent layers to simulate the effect of differential smoothing in SURF96, but we found that this did not improve the convergence to a best-fit model. Eventually, we just used the best-fit cost function. We run the algorithm for 300 generations with 40 models in each generation.

The method is not strictly comparable to SURF96 as the genetic method does not solve for density and fixes the P-wave velocity according to a prescribed equation. But the input data is the same and the parameters that describe each framework (e.g., number of layers, etc.) are comparable. With these limitations in mind, we chose three sample nodes and ran the genetic algorithm with five different seeds to the random number generator that starts the program at each node. The input data are the values of dispersion for every $0.5 \mathrm{~s}$ from $3.5 \mathrm{~s}$ to $18 \mathrm{~s}$ (31 points). The dispersion curve and the best model out of five for each node is shown in Fig. 5. The parameters used are given in Table 2, which sets the number of generations, the number of models in each generation, the range of various parameters such as shear-wave velocity. To calculate the error, we computed the standard deviation of the five best models from the five runs, which is also plotted in Fig. 5. As an aside, the original program tried to form a consensus model from the best model (closest fit to the original dispersion data) plus all models within some percentage (say 3\%) of the error for the best model and then form a final model by averaging all of the models in that set. This did not produce a good-fitting model to the dispersion data, suggesting a consistent bias in goodfitting, but not best-fitting models. Instead, we settle on using the best fit from each of the five runs and comparing those models.

From Fig. 5 left side, it is apparent that the fits to the dispersion curves from running the forward problem for the best model are remarkably good fits to the observed data. Two of the three show a close fit of the velocity values from the genetic algorithm to those from SURF96 (Fig. 5 right side). The genetically derived velocity values for node 40-50 ( $x$ and $y$ indices) are slightly higher at depths less than $7 \mathrm{~km}$ and lower at depths below $7 \mathrm{~km}$. The error bars nicely bracket the estimates of velocity for node $30-40$, but the estimates of velocity fall near the limits for node 40-50. The error bars are remarkably tight for node 50-55. This comparison suggests that the velocity models from SURF96 are close to those from an unbiased global optimization search for equivalent models. Because SURF96 can be run more 
Results from Genetic inversion

(a)

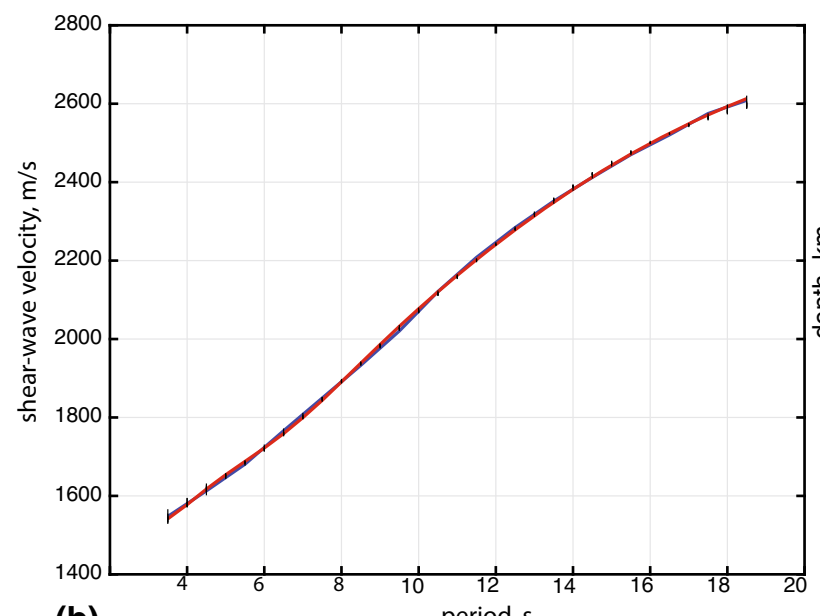

Node $x=30, y=40$

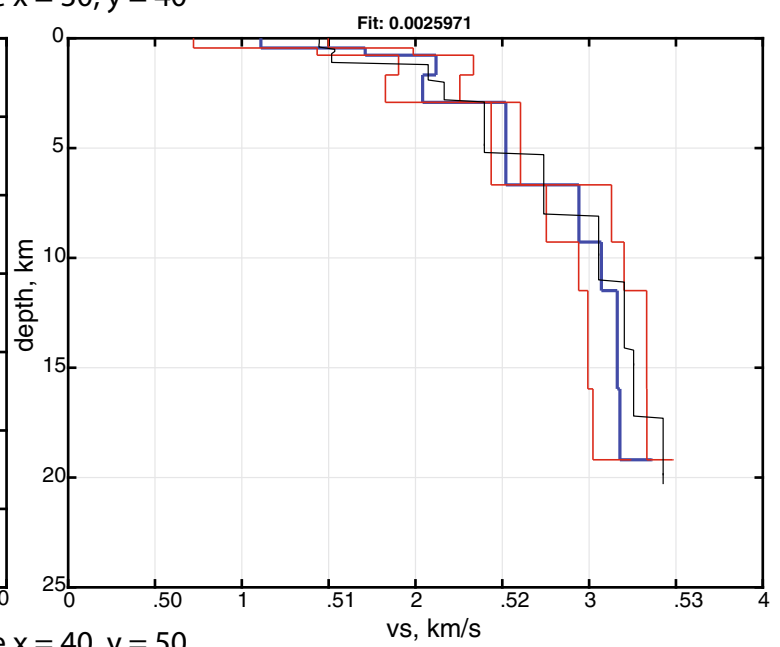

(b)
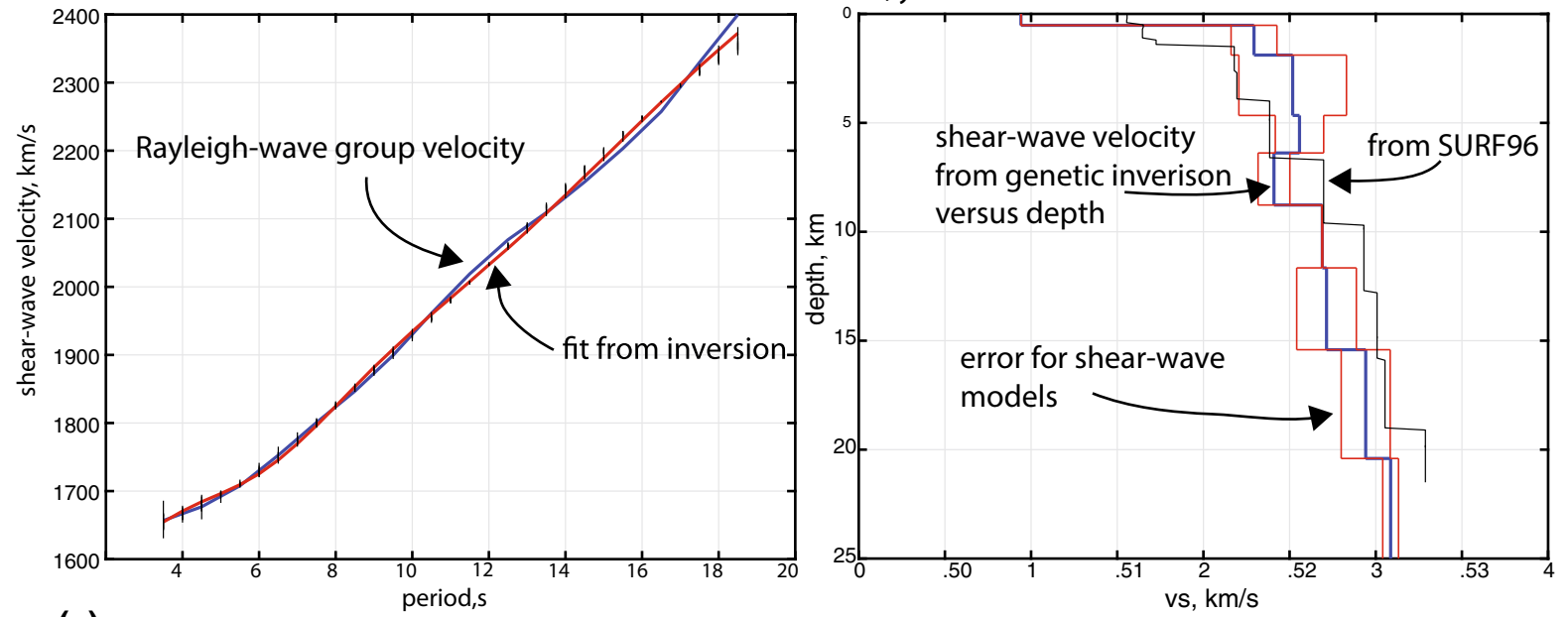

(c)

Node $x=50, y=55$
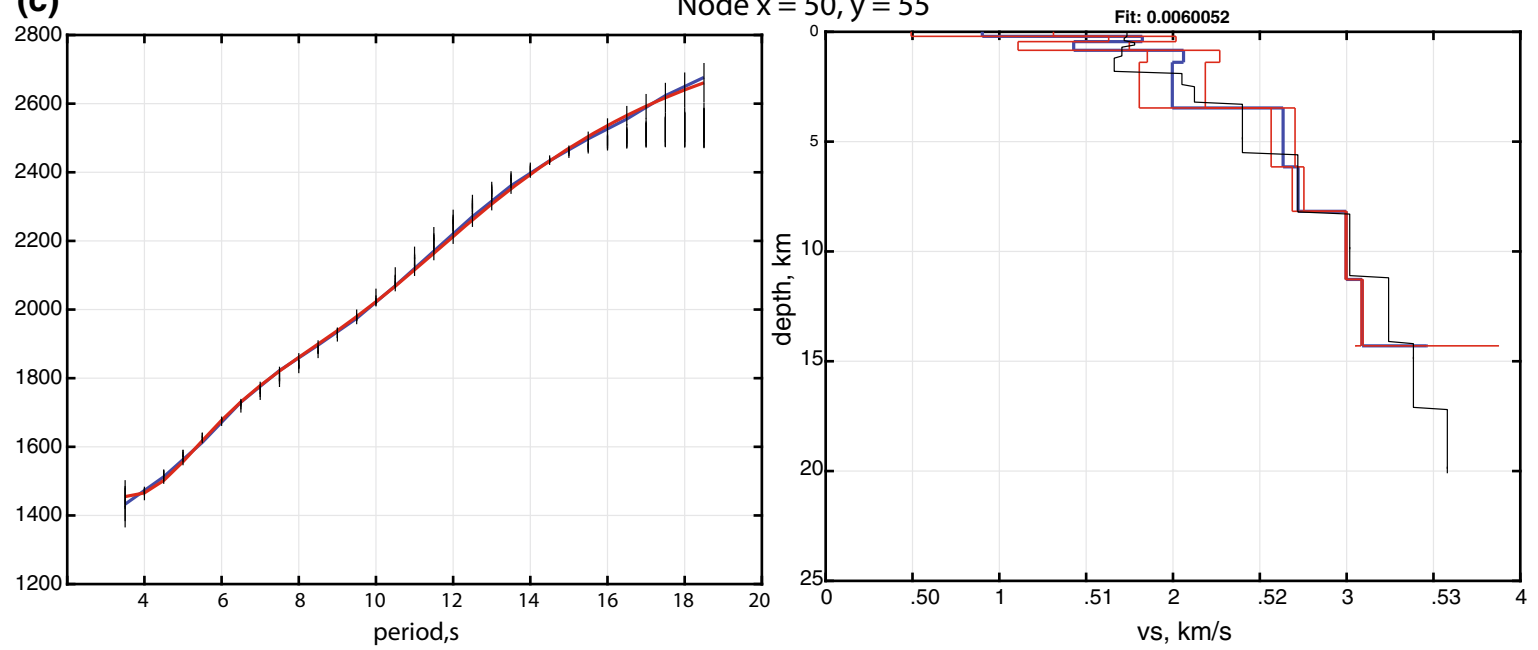
Figure 5

Observed and calculated dispersion curves for three nodes (nodes run from 1 to 101 east-west and 1 to 101 north-south). The blue line is the observed Rayleigh wave group velocity, red is calculated from the best model using the genetic algorithm. The thin red lines in the right-hand plots are estimates of error from calculating the standard deviation of the best models from the five runs. The gray

line is the estimate for that node from the SURF96 inversion

Table 2

Parameters for using genetic algorithm

\begin{tabular}{ll}
\hline Parameter & Value \\
\hline Seed value & $1-5$ \\
Population size & 40 \\
Maximum generation & 300 \\
Crossover rate & 0.7 \\
Modulation rate & 0.01 \\
Model parameters & 10 layers, etc. \\
Range in velocity of first layer $(\mathrm{km} / \mathrm{s})$ & $0.8-1.8$ \\
Split into how many values & 8 \\
Density (gm/cc) & 1.8 \\
Range in thickness (km) & $0.2-1.0$ \\
Split into how many values & 8 \\
Repeat for 9 more layers & $\ldots$ \\
\hline
\end{tabular}

Seed value is the number given to a random number generator to start the program. We ran the program five times for each node

There are 40 chromosomes (or models) in each generation

The program was run for 300 generations (or iterations)

The crossover rate refers to a pairing of chromosomes and exchanging sections of the binary code that describes each individual

Some genes in each chromosome are changed and this process is controlled by the mutation rate

The crossover rate and modulation rate refer to parameters that control mutation

The number of layers has to be specified and we used ten layers to emulate the model used in SURF96, but we set the limit to slightly less to stabilize the program

For example, there were eight velocities in the range of $0.8-1.8 \mathrm{~km} / \mathrm{s}$ in the top layer. The program then only searched over these eight values to find a best-fitting value

efficiently we use SURF96 to invert for the final, complete model.

\section{Depth Resolution}

The sensitivities of the Rayleigh waves to different depth intervals are shown in Fig. 6 (Fletcher et al. 2016). The Rayleigh wave sensitivities are a function

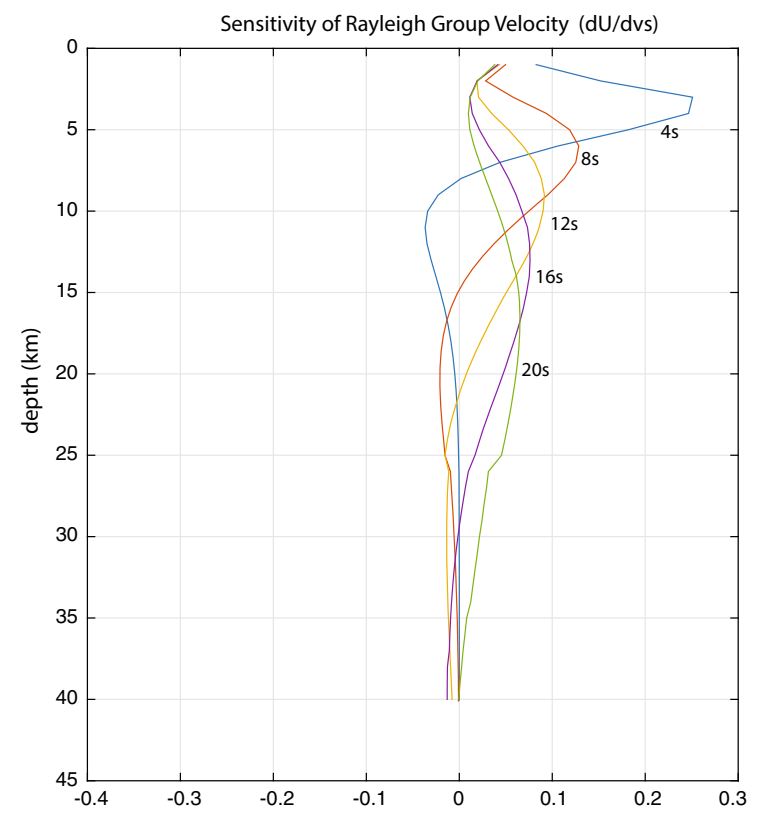

Figure 6

Sensitivity of the Rayleigh wave data versus depth. Note that the longer periods are more sensitive to the greater depths. Note that the shortest periods (about $4 \mathrm{~s}$ ) have some sensitivity at shallow depths

of period with the shortest period being more sensitive to the upper few kilometers. The $4 \mathrm{~s}$ period peaks between 3 and $4 \mathrm{~km}$ depth but is above 0.10 until it is shallower than $1 \mathrm{~km}$ (peak is at a value of 0.3 for comparison). Consequently, the data (Rayleigh wave group velocities at around $4 \mathrm{~s}$ period) are probably not sensitive to the shear-wave velocity at depths of just a few hundred meters.

\section{Results}

Maps of spatial averages of the complete velocity model using SURF96 in selected depth intervals are shown in Fig. 7 with local faults. We averaged over $2 \mathrm{~km}$ intervals to suppress noise or small scale anomalies. Smoothing has been applied to the 3-D model in addition to the averaging over depth for each image. The kernel for smoothing covers three nodes in each horizontal dimension. This smoothing is done only in the horizontal dimension. There is no smoothing in the plotting function. The algorithm fills out every node in the defined space (which covers 


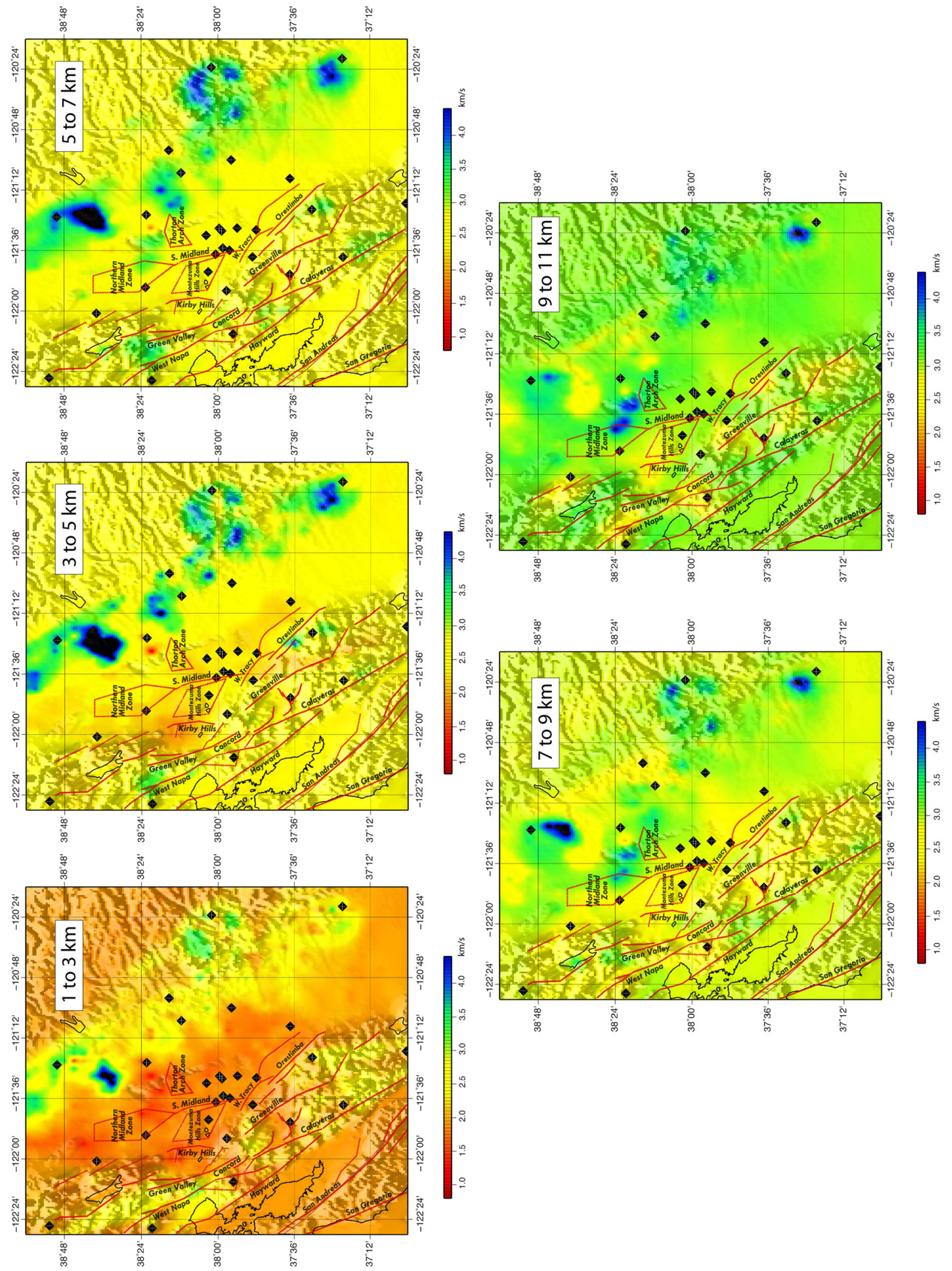


Figure 7

Maps of the spatial distribution of shear-velocity at various depth intervals. Each map is an average over $2 \mathrm{~km}$ with shallowest on the left. The values of shear-wave velocity have been smoothed in the horizontal dimension using a kernel of 3. Color map ranges from 0.8 to $4.5 \mathrm{~km} / \mathrm{s}$. Also shows local faults in the Central Valley and eastern Coast Ranges. The colors near the edge of the figure are default values and Fig. 3 should be used to judge which nodes are well determined. The Rio Vista basin is approximately co-located with the Montezuma Hills zone. The faulting and other features are from DRMS (2006)

most of Central Valley and extends into the foothills of the Sierra Nevada Mountains and the Coast Ranges), whether rays are present or not. Many nodes near the edge of the map are given a default value, which is the average. This is necessary because the algorithm does not know ahead of time which nodes are crossed by rays. The weights, shown in Fig. 3, may be used to judge which nodes have values that are well determined. The map from 1 to $3 \mathrm{~km}$ mimics the map of the spatial distribution of $4.5 \mathrm{~s}$ Rayleigh wave group velocity (Fig. 2) with low velocities in the Central Valley compared to both the Sierra Nevada and Coast Ranges. Note that the color model shows absolute velocities over a broad range $(0.8-4.5 \mathrm{~km} / \mathrm{s})$ compared to the model of group velocity variations in Fletcher et al. (2016). In the shear-wave model, we see a low-velocity notch (red in color) north of $38^{\circ}$ on the western boundary of the Central Valley between the Kirby Hills and Green Valley faults, which was also prominent in the Rayleigh wave velocity data in Fletcher et al. (2016). Near the Montezuma Hills zone this region coincides with the Rio Vista basin, but the low velocities extend further to the west. In general, the shear-wave model has boundaries that fit well to the orientation and location of local faults in the western edge of the Central Valley. The eastern edge of the Central Valley has a scalloped appearance where low velocities of the upper Central Valley abut faster velocities in the Sierra Nevada foothills. The area around Mt. Diablo at $37.8^{\circ} \mathrm{N},-121.8^{\circ} \mathrm{W}$ also appears higher in velocity compared to the surroundings at shallow depths possibly due to more mafic rocks associated with the Mt. Diablo ophiolite (Williams 1984). At greater depths, the average velocities increase and the stark contrast in the Central Valley that is seen in the $1-3 \mathrm{~km}$ depth range becomes less prominent in the depth range of $3-5 \mathrm{~km}$ and absent at $9-11 \mathrm{~km}$, indicating the basement is more homogeneous across the Coast Ranges, Central Valley, and Sierra Nevada Mountains. Also, shown in Fig. 7 are local faults. The orientation and number of faults suggest the west side of the Central Valley is fault-controlled and the distribution of shear-wave velocities reflects the geometry of faults. For example, the westward notch at $38.2^{\circ} \mathrm{N}$ is reflected in the orientation of the Cordelia and Green Valley faults apparent in the $1-3 \mathrm{~km}$ depth image. There are spots of lower velocities (yellow in color) in the $9-11 \mathrm{~km}$ slice that are mostly correlated with the faulting on the west side of the Central Valley. One spot at $38.2^{\circ} \mathrm{N}$ is associated with the deeper sections of the Rio Vista basin.

The contrast between slow and fast velocities seems less at greater depths with the exception of a lineament of high velocities that trends NNW at the right edge of the array. Because this area is close to the eastern border of the stations used in the ambient noise studies (Fig. 1), the fast anomalies may not be real (one possibility is that there are high velocities in this region, but the shape is not well controlled). This lineament is close to a Central Valley high in aeromagnetics (Jachens et al. 1995), which may reflect an ophiolite terrane.

The slices shown in Fig. 8 show the asymmetric synclinal structure of the Central Valley (see crosssection in supplementary materials), particularly at about $38.2^{\circ} \mathrm{N}$ as shown in various geologic crosssections (e.g., Sullivan and Sullivan 2012) which probably reflects a back arc basin associated with the subduction of the Farallon plate. The Rio Vista Basin is apparent in slices of the model shown in Fig. 8. The basin is approximately at $38.2^{\circ} \mathrm{N}$ and between the Kirby Hills and South Midland faults. However, there is also a significant basin with low velocities near the surface to the west of the Kirby Hills fault. This is the region of the notch previously mentioned and is near the Montezuma Hills. There is a strong gravity low (Fletcher et al. 2016 and Langenheim, personal communication 2016) that marks the Rio Vista Basin, suggesting that the Rio Vista Basin is a major structure. While our data sees the Rio Vista Basin, it identifies another deeper, slower structure in the shallow crust just west of the Kirby Hills fault. 


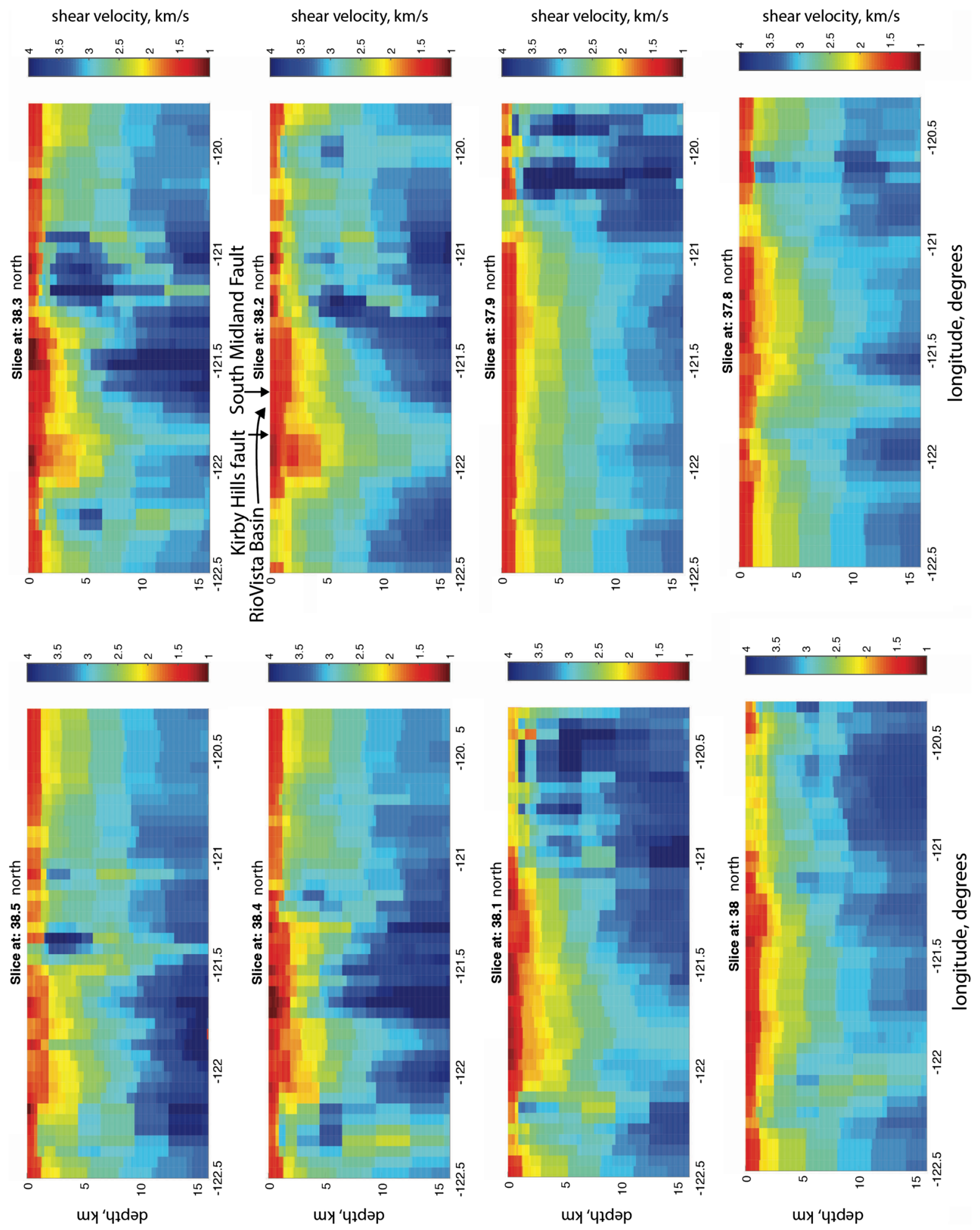


4 Figure 8

East-west $x-z$ slices through the model. The slices are displayed with $x$ (longitude) and $z$ (depth) axes. The slices are arranged in pairs (vertically) and go from the upper left to upper right to lower left. The color model goes from 1 to $4 \mathrm{~km} / \mathrm{s}$ for each frame
Interesting features of the Central Valley are included in Fig. 9 such as the major rivers of the western slope of the Sierra Nevada Mountains and the Stockton Arch (Barstow 1990), which is a major east-west basement high nar $38^{\circ} \mathrm{N}$ that demarcates

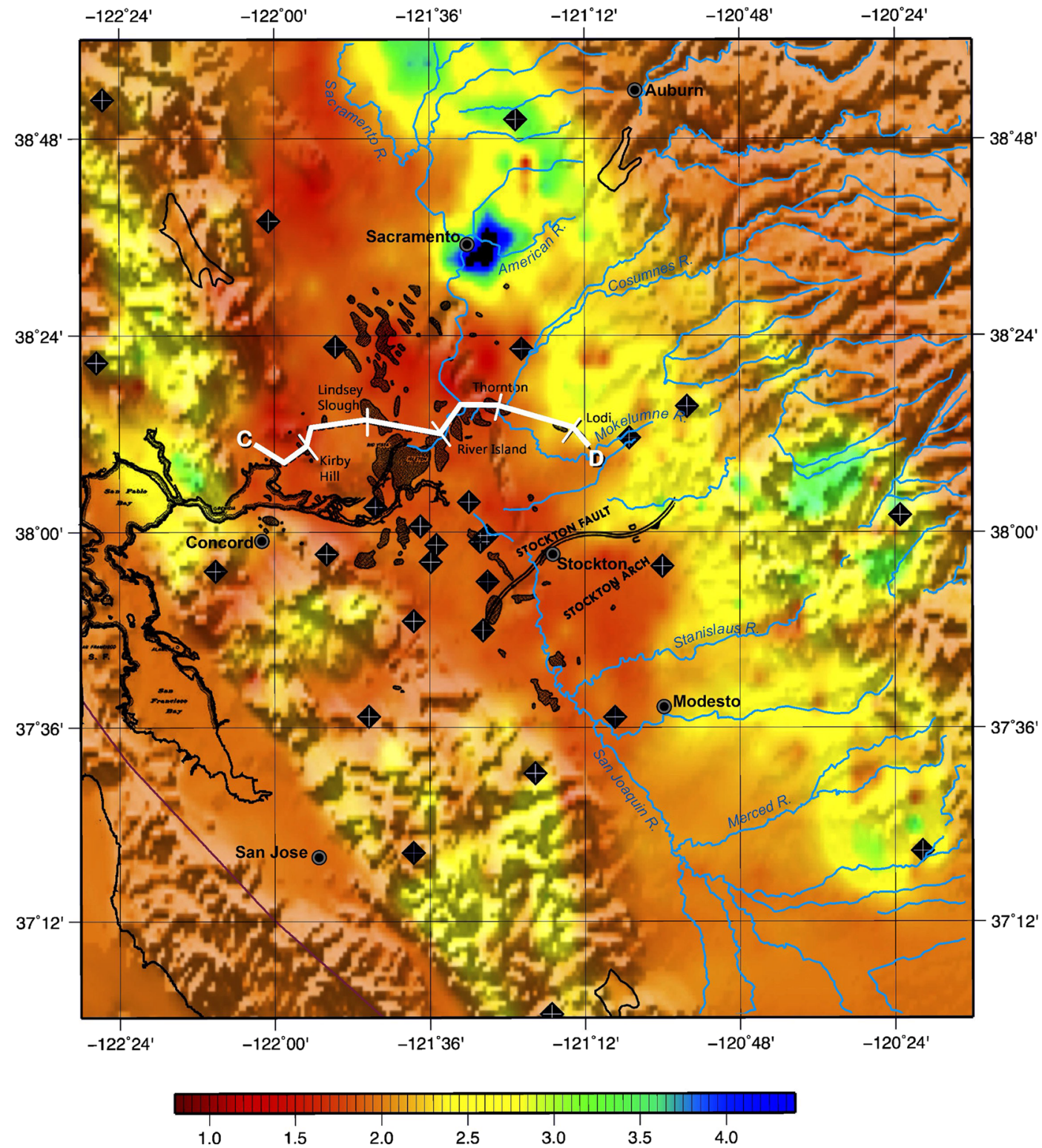

Figure 9

The image from Fig. 7 for the 1-3 km depth and geologic features of the Central Valley such as the Stockton Arch and gas fields (dark patches). The cross-section from supplementary materials is noted as C-D in the figure. Major rivers draining the Sierra Nevada Mountains 
the north Central Valley from the South. The rivers, such as the Cosumnes and Mokelumne, and Stanislaus seem to correlate with slow velocities in the shallow western Sierra Nevada Mountains although the American River does not (it is located near a large patch in the image that is poorly determined). The Stockton fault falls in a slight local high in velocities just north of a patch of lower velocities (dark red in color) directly correlated with the location of the Stockton Arch. The correlation is stronger in the 7-9 km image in Fig. 7. The dark gray patches, which are mostly gas producing zones are correlated with slow velocity regions. The location of the crosssection included in supplementary materials is shown as white line labeled $\mathrm{C}-\mathrm{D}$ and shows the asymmetrical synclinal form of the Central Valley.

Lin et al. (2010) provide a state-wide P- and $\mathrm{S}$-wave velocity model from inverting arrival times at local and regional networks. Unfortunately, the area around the Delta has few estimates of S-wave velocity presumably from lack of adequate ray coverage. However, they show a southwest-northeast cross-section in P-wave velocity (7b in Lin et al. 2010) that is close to the Delta. Lin et al. (2010) find low velocities associated with the shallow Central Valley similar to the ones depicted in Figs. 7 and 8. They also show higher velocities at depths of about $10 \mathrm{~km}$ under the Central Valley similar to that shown for $38.4^{\circ}$ and $38.2^{\circ}$ cross-sections in Fig. 8. Although there can be varying $V \mathrm{p} / V \mathrm{~s}$ ratios, the $\mathrm{P}$-wave velocity model of Lin et al. (2010) appears similar to the S-wave model in this study.

\section{Conclusions}

3-D Rayleigh wave group velocities for the Central Valley, California, have been inverted for shearwave velocity using a linear, least squares routine and compared with the result from using a genetic algorithm. The region covers most of the central and northern Central Valley centered on the Sacramento/ San Joaquin Delta. This model will facilitate the simulation of ground motions in the Delta from sources at local and regional faults. Features of the model show low velocities at shallow depths (less than $3-5 \mathrm{~km}$ ) in the Central Valley compared to either the Coast Ranges to the west or the foothills of the Sierra Nevada Mountains to the east. This shearwave velocity model reflects the tectonic history of the region where the Central Valley was a forearc basin from the subduction of the Farallon plate. In particular, low shear velocities are associated with the Rio Vista Basin and extend further to the west near the Potrero and Kirby Hills faults. At greater depths, the contrast is not as strong with spots of low velocities in the eastern Coast Ranges compared to the average. Mt. Diablo is visible as a local high at shallow depths. A lineament of high velocities near the eastern edge of the Central Valley may be caused by an ophiolite body associated with a high in aeromagnetic and gravity data, however, it is near the eastern edge of the array of stations used in the ambient noise tomography, and consequently the spatial resolution is poor in this region. Simulations using this model will permit a better estimate of the seismic hazard to the Delta, one of the California's most important resources.

\section{Acknowledgements}

The original study on the spatial distribution of Rayleigh wave velocities was facilitated by Kevin Seats and Jesse Lawrence in the Geophysics Department at Stanford University. We are indebted to Larry Baker at the US Geological Survey for extensive software support. We thank H. Yamanaka for sharing his genetic code for inverting Rayleigh wave group velocities. The code SURF96 is available as part of the package "Computer Programs in Seismology", by Robert Herrmann and is available through the web. The seismic data used for the tomographic inversion is at the IRIS DMC under the network code YU and is freely available. Any code or data can be obtained by contacting the authors.

Open Access This article is distributed under the terms of the Creative Commons Attribution 4.0 International License (http:// creativecommons.org/licenses/by/4.0/), which permits unrestricted use, distribution, and reproduction in any medium, provided you give appropriate credit to the original author(s) and the source, provide a link to the Creative Commons license, and indicate if changes were made. 


\section{REFERENCES}

Atwater, T. (1970). Implications of plate tectonics for the Cenozoic tectonic evolution of the Western North America. Geological Society of America Bulletin, 81, 3513-3536.

Barmin, M. P., Ritzwoller, M. H., \& Levshin, A. L. (2001). A fast and reliable method for surface wave tomography. Pure and Applied Geophysics, 158, 1351-1375.

Bartow, J. A. \& Nilsen, T. H. (1990). Review of the Great Valley sequence, eastern Diablo Range and the northern San Joaquin Valley, central California, US Geological Survey Open-file Report 90-226, (p. 25).

California Department of Conservation, Division of Oil, Gas and Geothermal Resources. (1982). California Oil and Gas Fields, Volume III-Northern California 4th edn. (pp. 330).

Campillo, M., \& Paul, A. (2003). Long-range correlations in the diffuse seismic coda. Science, 299, 547-549.

Constenius, K. N., Johnson, R. A., Dickinson, W. R., \& Williams, W. A. (2000). Tectonic evolution of the Jurassic-Cretaceous Great Valley forearc, California: implications for the Franciscan thrust-wedge hypothesis. GSA Bulletin, 112, 1703-1723.

Delta Risk Management Strategy (DRMS). (2006). Probabilistic seismic hazard analysis for ground shaking and estimation of earthquake scenario probabilities prepared for California Department of Water Resources Report, by URS Corp./Jack Benjamin and Assoc., p. 32.

Fletcher, J. B., Erdem, J., Seats, K., \& Lawrence, J. (2016). Tomographic Rayleigh-wave group velocities in the Central Valley, California centered on the Sacramento/San Joaquin Delta. Journal of Geophysical Research. doi:10.1002/ 2105JB012376.

Gibbs, J. F., Boore, D. M., Tinsley, J. C., Mueller, C. S. (2001) Borehole P- and S- wave velocity at thirteen stations in southern California, U.S. Geological Survey Open-file Report 01-506, p. 122

Godfrey, N. J., \& Klemperer, S. L. (1998). Ophiolitic basement to a forearc basin and implications for continental growth: the Coast Range/Great Valley ophiolite, California. Tectonics, 17, 558-570.

Goldberg, D. E. (1989). Genetic algorithms (p. 412). Boston: Addison-Wesley.

Herrmann, R. B. (2013). Computer programs in seismology: an evolving tool for instruction and research. Seismological Research Letters, 84, 1081-1088. doi:10.1785/0220110096.
Jachens, R. C., Griscom, A., \& Roberts, C. W. (1995). Regional extent of Great Valley basement west of the Great Valley, California: implications for extensive tectonic wedging in the California Coast ranges. Journal of Geophysical Research, 100, 12769-12790.

Lin, G. C. H., Thurber, H., Zang, E., Hauksson, P., Shearer, F., Waldhauser, T. M. Brocher, et al. (2010). A California statewide three-dimensional seismic velocity model from both absolute and differential times. Bulletin of the Seismological Society of America, 100, 225-240.

Nafe, J. E., \& Drake, L. (1957). Variation with depth of shallow and deep water marine sediment of porosity, density and the velocities of compressional and shear waves. Geophysics, 22, 523-552.

Romanowicz, B. (2002). Inversion of surface waves: a review. International Handbook of Earthquake and Engineering Seismology, 81a, 149-173.

Russell, D. R. (1987). Multi-channel processing of dispersed surface waves, Dissertation St. Louis University, 1-162.

Sen, M. K., \& Stoffa, P. L. (1992). Rapid sampling of model space using genetic algorithms: examples from seismic waveform inversion. Geophysical Journal International, 108, 282-292.

Shapiro, N. M., Campillo, M., Stehly, L., \& Ritzwoller, M. H. (2005). High-resolution surface-wave tomography from ambient seismic noise. Science, 307, 1615-1618.

Shapiro, N. M., \& Ritzwoller, M. H. (2002). Monte Carlo inversion for a global shear-velocity model of the crust and upper mantle. Geophysical Journal International, 151, 88-105.

Sullivan, R., \& Sullivan, M. D. (2012). Sequence stratigraphy and incised valley architecture of the Domengine formation, Black Diamond Mines Regional Preserve and the southern Sacramento Basin, California. Journal of Sedimentary Research, 82, 781-800.

Warren, L. M., Snoke, J. A., \& James, D. E. (2008). S-wave velocity structure beneath the high lava plains, Oregon, from Rayleigh-wave dispersion inversion. Earth and Planetary Science Letters, 274, 121-131.

Williams, K. M. (1984). Geologic map and cross sections of the Coast Range Ophiolite at Mount Diablo, Contra Costa County, California, US Geological Survey Open-File Report, (pp. 84-553).

Yamanaka, H., \& Ishida, H. (1996). Application of genetic algorithms to an inversion of surface-wave dispersion data. Bulletin of the Seismological Society of America, 86, 436-444. 